\title{
Evaluation of the Portuguese Ornamental Stone Resources
}

\author{
Jorge M. F. Carvalho', a , José V. Lisboa ${ }^{1, b}$, António Casal Moura ${ }^{1, c}$, \\ Cristina Carvalho ${ }^{1, d}$, Luís M. O. Sousa ${ }^{2, e}$ and Mário M. Leite ${ }^{1, f}$ \\ ${ }^{1}$ Laboratório Nacional de Energia e Geologia, Apartado 7586 - Alfragide, 2610-999 Amadora, \\ Portugal \\ ${ }^{2}$ Departamento de Geologia, Universidade de Trás-os-Montes e Alto Douro, Apartado 1013, 5001 - \\ 801 Vila Real, Portugal \\ ajorge.carvalho@Ineg.pt, ${ }^{b}$ vitor.lisboa@Ineg.pt, ${ }^{c}$ casal.moura@Ineg.pt, ${ }^{d}$ cristina.carvalho@Ineg.pt, \\ eIsousa@utad.pt, ' ${ }^{\mathrm{f}}$ machado.leite@Ineg.pt
}

Keywords: Ornamental Stones, Portugal, Resource Evaluation.

\begin{abstract}
Portugal produces a great diversity of ornamental stones. Besides the internationally known white and pink marbles, also light cream limestones are produced, as well as grey, yellow and pink granites, and dark grey slates.

A first exercise is presented on the evaluation of the available resources of ornamental stones in the whole Portuguese territory. The results show a total availability of 410 million cubic meters, of which 274 million refer to granite, 76 million to limestone, 51 million to marble, and 9 million to slate.
\end{abstract}

\section{Introduction}

Portugal is one of the world's leading producers of ornamental stones. It has a rich variety of this kind of mineral resources, which are exploited all over the country in several mining sites. As a result of the systematic inventory of those mining sites, carried out by the Portuguese Geological Survey since long time ago, most of the ornamental varieties produced are known and have been technically characterized.

Granite type ornamental stones are mainly exploited in the central and northern regions of the country's territory. The most abundant present greyish colours and a great diversity of textures but there are also pink and yellow varieties, which are the most valuable [1]. Marbles are exploited in the Alentejo region, notably in the so-called Anticlinal de Estremoz [2]. They present a large spectrum of colours, from white to dark grey, but the most common are the light-cream coloured with streaks of different tonalities. Pale to deep pink varieties are the most valuable. With respect to limestones, the largest mining district is the Maciço Calcário Estremenho (MCE), located $150 \mathrm{~km}$ north of Lisbon [2]. They are cream coloured and, depending on the way the blocks are cut, they may show a texture marked by thin sedimentary laminations. Nowadays, these limestones are the most required Portuguese ornamental stones, especially by the Chinese market. Portugal also produces slates but in limited quantities in small mining sites.

The terms employed here to refer the main groups of ornamental stones should be understood according to the nomenclature commonly used in the commercial transactions of these raw materials [3].

Despite the thorough knowledge concerning the characteristics of the Portuguese ornamental stones and some resource measurements in restricted places, there is no concrete knowledge about the overall amount of available resources. This work presents a first attempt on the quantification of the available ornamental stone resources in Portugal.

\section{Data and Methodology}

The data that form the basis of this work results from the systematic inventory of ornamental stone resources developed by the Portuguese Geological Survey. It is supported on field works at various levels. From simple recognition studies of the mining sites and ornamental varieties therein 